\title{
The susceptibility of five African Anopheles species to Anabaena PCC 7120 expressing Bacillus thuringiensis subsp. israelensis mosquitocidal cry genes
}

Irene Ketseoglou and Gustav Bouwer

\begin{abstract}
Background: Malaria, one of the leading causes of death in Africa, is transmitted by the bite of an infected female Anopheles mosquito. Problems associated with the development of resistance to chemical insecticides and concerns about the non-target effects and persistence of chemical insecticides have prompted the development of environmentally friendly mosquito control agents. The aim of this study was to evaluate the larvicidal activity of a genetically engineered cyanobacterium, Anabaena PCC 7120\#11, against five African Anopheles species in laboratory bioassays.

Findings: There were significant differences in the susceptibility of the anopheline species to PCC 7120\#11. The ranking of the larvicidal activity of PCC $7120 \# 11$ against species in the An. gambiae complex was: An. merus < An. arabiensis $<$ An. gambiae < An. quadriannulatus, where < indicates a statistically lower $L C_{50}$. The $L C_{50}$ of $P C C$ $7120 \# 11$ against the important malaria vectors An. gambiae and An. arabiensis was $12.3 \times 10^{5}$ cells $/ \mathrm{ml}$ and $8.10 \times$ $10^{5}$ cells/ml, respectively. PCC $7120 \# 11$ was not effective against An. funestus, with less than $50 \%$ mortality obtained at concentrations as high as $3.20 \times 10^{7}$ cells $/ \mathrm{ml}$.

Conclusions: PCC 7120\#11 exhibited good larvicidal activity against larvae of the An. gambiae complex, but relatively weak larvicidal activity against $A n$. funestus. The study has highlighted the importance of evaluating a novel mosquitocidal agent against a range of malaria vectors so as to obtain a clear understanding of the agent's spectrum of activity and potential as a vector control agent.
\end{abstract}

Keywords: Malaria vectors, Anopheles, Bacillus thuringiensis subsp. israelensis, Cry proteins, Cyanobacteria, Anabaena sp. PCC 7120, Genetic engineering, Bioassays, Larvicidal activity

\section{Background}

Species within the genus Anopheles (Diptera: Culicidae) play a major role in the transmission of malaria in Africa, in particular mosquitoes from the An. gambiae complex and the An. funestus group [1,2]. The An. gambiae complex contains excellent and efficient vectors of malaria (An. gambiae s.s. and An. arabiensis), as well as minor vectors (An. merus) and non-vectors (An. quadriannulatus species A and B) [1]. The An. funestus group contains an important vector of malaria, An. funestus s.s. [2].

\footnotetext{
* Correspondence: gustav.bouwer@wits.ac.za

School of Molecular and Cell Biology, University of the Witwatersrand, Private Bag 3, Wits 2050, Johannesburg, South Africa
}

Although chemical insecticides have been used successfully in integrated vector control programs [3], many malaria vector control programs are hampered by the development of resistance of the vectors to chemical insecticides [4-6]. In addition to development of resistance, concerns about the non-target effects and persistence of the chemical insecticides have prompted the development of environmentally friendly control agents and control programs [7].

Bacillus thuringiensis subsp. israelensis (Bti) is a Gram-positive, aerobic, spore-forming, bacterium that produces crystalline inclusions that contain crystal (Cry) or cytolytic (Cyt) proteins that are highly toxic to

\section{Biomed Central}


mosquito larvae $[8,9]$. Although there is low risk of resistance being developed to Bti [10], there are several disadvantages to using Bti as a control agent $[11,12]$. These include its low persistence in the field due to inactivation by $\mathrm{UV}$, ingestion of $B t i$ by other aquatic organisms, and the settling of Bti from the mosquito larval feeding zone [11-13]. One strategy to overcome some of the disadvantages of $B t i$ is to clone the cry genes of Bti into aquatic microorganisms that: (1) are not toxic to other organisms, (2) inhabit and persist in the larval feeding zone, (3) are used by mosquito larvae as a food source, (4) express Cry proteins at levels that are mosquito larvicidal, and (5) have cell walls that reduce inactivation of the Cry proteins by UV [13-15].

Xiaoqiang et al. [15] inserted the Bti cry $4 A a$, cry11Aa, and $p 20$ genes under the control of two tandem promoters (cyanobacterial constitutive promoter, $P_{p s b A}$, and Escherichia coli T7 early promoter, $P_{A I}$ ) into a filamentous nitrogen-fixing cyanobacterium, Anabaena sp. strain PCC 7120 (PCC 7120). The Bti genes are integrated into the chromosome of PCC 7120, resulting in a stable recombinant strain [16]. Laboratory bioassays have shown that the resultant recombinant strain, PCC 7120\#11, is a very effective larvicidal agent against Aedes aegypti $[13,15,16]$.

To our knowledge, no studies have examined the larvicidal activity of PCC 7120\#11 against several African malaria vectors. The aim of this study was, thus, to evaluate the larvicidal activity of PCC $7120 \# 11$ against five African Anopheles species in order to determine if PCC 7120\#11 may have potential as a malaria vector control agent.

\section{Methods}

Larvicidal activity of PCC $7120 \# 11$ was determined by laboratory bioassays against four species in the An. gambiae complex and one species in the An. funestus group. The An. gambiae complex species used in the study were (origin, colony name, and colonisation date provided): An. gambiae s.s. (Ibadan, Nigeria; NAG; 2001), An. arabiensis (Kanyemba, Zimbabwe; KGB; 1975), An. merus (KwaZulu-Natal, South Africa; MAF; 1988), and An. quadriannulatus species A (Sangwe, Zimbabwe; SANGWE; 1998). The species from the An. funestus group that was used in the study was An. funestus s.s. (Maputo, Mozambique; FUMOZ; 2000).

The anopheline mosquito species were obtained from colonies maintained at the National Institute of Communicable Diseases (Johannesburg, South Africa). Since the activity of PCC $7120 \# 11$ against $A$. aegypti had been previously evaluated [15], we included it as a control in the bioassays. The A. aegypti larvae were obtained from the South African Bureau of Standards (Pretoria, South Africa).
PCC 7120 and PCC 7120\#11, were cultured in BG-11 medium [15], at $30^{\circ} \mathrm{C}$ under continuous illumination (2000 lux) with constant agitation [13,16]. The PCC 7120 and PCC 7120\#11 cells were harvested by differential centrifugation and the cell concentration was determined by haemocytometer counts. Two millilitres of the appropriate dilution (covering an in-cup concentration range of $1.00 \times 10^{4}$ to $3.20 \times 10^{7}$ cells $/ \mathrm{ml}$ ) of either PCC 7120 or PCC $7120 \# 11$ was added to $130 \mathrm{ml}$ plastic cups that contained $98 \mathrm{ml}$ sterile distilled water and 20 thirdinstar mosquito larvae. In the case of An. merus, a sterile $5 \mathrm{M}$ saline solution was used instead of sterile distilled water.

Larvicidal activity was determined 24 hours postinoculation, with larvae presumed dead if they did not move when prodded. An untreated control (sterile distilled water) was included in the bioassays. If mortality in the controls (PCC 7120 and untreated) exceeded $5 \%$, the test was discarded and repeated. Each bioassay was repeated in triplicate on different days. The lethal concentration $\left(\mathrm{LC}_{50}\right.$ and $\left.\mathrm{LC}_{90}\right)$ for each species was determined by probit analysis [17]. For each species, probit analysis was based on the mortality data obtained from five PCC $7120 \# 11$ concentrations.

\section{Results and discussion}

The concentration-mortality data for the mosquito species are summarised in Table 1 . The heterogeneity factors for the different mosquito species evaluated were all less than one, indicating a good fit of the concentrationmortality data to the probit model [18].

The concentration-mortality regression slopes indicate the variability in response to a toxin within the vector population being examined [19]. In this study, An. arabiensis had a significantly steeper slope than the other species evaluated, suggesting that An. arabiensis had lower response variability or reduced heterogeneity in its population compared to the other mosquito species examined. The shallower slopes of the concentrationmortality regression lines obtained for An. gambiae and An. quadriannulatus mean that there are larger differences between the $\mathrm{LC}_{50}$ and $\mathrm{LC}_{90}$ values for these species than for the other anopheline species evaluated.

Although slight variation in $\mathrm{LC}_{50} \mathrm{~s}$ between studies may be expected due to differences in experimental conditions such as rearing conditions of the larvae and natural variations in the larval populations [20], the susceptibility of $A$. aegypti larvae to PCC 7120\#11 in this study was comparable to that $\left(\mathrm{LC}_{50}\right.$ of $0.9 \times 10^{5}$ cells/ $\mathrm{ml})$ previously reported by Xiaoqiang et al. [15]. However, the $\mathrm{LC}_{50}$ value of PCC $7120 \# 11$ against $A$. aegypti larvae was significantly lower than those of the anopheline species evaluated (Table 1). The decreased susceptibility of anopheline larvae compared to A. aegypti larvae 
Table 1 Probit analysis of concentration-mortality data for Anabaena PCC 7120\#11 against third instar mosquito larvae

\begin{tabular}{|c|c|c|c|c|}
\hline Species & $\mathrm{LC}_{50}\left(10^{5} \text { cells } / \mathrm{ml}\right)^{*}$ & $\mathrm{LC}_{90}\left(10^{5} \text { cells } / \mathrm{ml}\right)^{*}$ & Slope $\pm \mathrm{SE}^{\dagger}$ & Heterogeneity $\ddagger$ \\
\hline A. aegypti & $1.42(1.12-1.76)^{a}$ & $8.21(6.05-12.3)^{a}$ & $1.70 \pm 0.15^{a}$ & 0.75 \\
\hline An. merus & $3.90(3.58-4.17)^{\mathrm{b}}$ & $9.30(8.0-11.4)^{a}$ & $3.37 \pm 0.31^{b}$ & 0.62 \\
\hline An. arabiensis & $8.10(7.62-8.56)^{c}$ & $14.3(12.8-16.5)^{b}$ & $5.18 \pm 0.46^{c}$ & 0.19 \\
\hline An. gambiae & $12.3(11.4-13.3)^{d}$ & $35.1(29.5-44.9)^{c}$ & $2.81 \pm 0.24^{d}$ & 0.49 \\
\hline An. quadriannulatus & $15.7(14.3-17.3)^{\mathrm{e}}$ & $43.0(35.9-54.9)^{c}$ & $2.93 \pm 0.26^{\mathrm{bd}}$ & 0.92 \\
\hline An. funestus & N.D. & N.D. & N.D. & N.D. \\
\hline
\end{tabular}

* Values in brackets show the 95\% fiducial limits (FLs). Values in a column followed by the same letters are not significantly different (overlapping $95 \%$ FLs).

${ }^{+}$Slope \pm standard error. Values followed by the same letters are not significantly different $(p>0.05)$.

Heterogeneity factor $=x^{2} /$ d.f. (degrees of freedom).

${ }^{\S}$ Not determined. Less than $50 \%$ mortality was obtained even at concentrations as high as $3.2 \times 10^{7}$ cells $/ \mathrm{ml}$.

may be due to differences in feeding behaviour [21]; Anopheles larvae (surface feeders) may ingest fewer PCC $7120 \# 11$ cells than $A$. aegypti larvae that feed at all levels in the water column.

The $\mathrm{LC}_{50}$ values differed significantly between the anopheline species examined, with PCC $7120 \# 11$ being most effective against An. merus larvae (Table 1). On the basis of $\mathrm{LC}_{50}$ ratios, the larvae of An. quadriannulatus were 4-fold less susceptible to PCC 7120\#11 than the larvae of An. merus. PCC $7120 \# 11$ had relatively weak larvicidal activity against $A n$. funestus, even at concentrations as high $3.2 \times 10^{7}$ cells $/ \mathrm{ml}$. The $\mathrm{LC}_{90}$ values for An. merus and $A$. aegypti were significantly lower than the $\mathrm{LC}_{90}$ values for An. arabiensis, An. quadriannulatus, or An. gambiae (Table 1). Furthermore, the $\mathrm{LC}_{90}$ for $A n$. arabiensis was significantly lower than that of An. quadriannulatus or An. gambiae (Table 1).

The significant differences in susceptibility to PCC 7120\#11 between the anopheline species may reflect species-specific differences in one or more of the steps in the ingestion-to-toxicity process. For example, differences in the ingestion rate or efficiency of digestion of PCC $7120 \# 11$ cell walls by the different anopheline species may significantly affect the concentration of Cry proteins in the larval midgut. However, preliminary evaluations (unpublished data) did not show marked differences in the ingestion or digestion rates between $A n$. funestus and An. arabiensis.

A factor to consider in interpreting the significant differences in susceptibility between An. funestus and species of the $A n$. gambiae complex is the combination of the toxins present in PCC 7120\#11. Bti, which naturally produces crystals that contain the toxins Cry4Aa, Cry4Ba, Cry10Aa, Cry11Aa, Cyt1Aa and Cyt2Ba [9,22], has higher larvicidal activity against mosquitoes than recombinant clones containing a subset of toxins $[9,23,24]$. In a previous study [25], Bti strain HD522 was evaluated against the same anopheline species, with An. funestus larvae having an $\mathrm{LC}_{50}$ that was statistically similar to the $\mathrm{LC}_{50}$ values obtained for An. arabiensis, An. gambiae, and An. merus larvae. The comparatively low larvicidal activity of PCC $7120 \# 11$ against An. funestus could be due to the absence of the other Bti Cry and Cyt proteins in PCC 7120\#11, which produces only the Cry4Aa and Cry11Aa proteins. Since the larvicidal activity of Cry proteins is often correlated with the high affinity binding of the proteins to specific membrane-bound receptors in the larval midgut [26,27], the susceptibility differences could be due to inherent differences between the species in the structure or density of midgut receptors for Cry4Aa or Cry11Aa. In this context, it is noteworthy that Cyt1A is known to synergize Cry11A toxicity by functioning as a membrane-bound receptor [28]. Further research is required to determine which combinations of the Cry and Cyt proteins would result in the highest larvicidal activity against $A n$. funestus larvae.

PCC 7120\#11 displayed good larvicidal activity against key malaria vectors, including An. gambiae and An. arabiensis. Although PCC $7120 \# 11$ displayed comparatively weak larvicidal activity against $A n$. funestus at economically practical concentrations, PCC $7120 \# 11$ may have potential as a larvicidal agent in geographic regions where An. funestus is not the predominant vector. Alternatively, PCC $7120 \# 11$ could be applied as a larvicidal agent as part of an integrated vector control program that targets An. funestus adults and the larvae of other malaria vectors. However, before PCC 7120\#11 can used in vector control programs, its effects on non-target organisms and its persistence in aquatic environments would have to be comprehensively evaluated.

\section{Competing interests}

The authors declare that they have no competing interests.

\section{Authors' contributions}

Conceived the idea: GB. Performed the experiment and analyzed the data: IK and GB. Contributed reagents/materials/analysis tools: GB. Wrote the manuscript: IK. Clarified the manuscript: GB. All authors read and approved the final manuscript.

\section{Acknowledgements}

The authors thank M. Coetzee and L.L. Koekemoer (Vector Control Reference Unit, National Institute for Communicable Diseases of the National Health 
Laboratory Service, Johannesburg, South Africa), for providing the Anopheles larvae and the South African Bureau of Standards (Pretoria, South Africa) for the A. aegypti larvae used in this study. The authors express gratitude to A. Zaritsky (Department of Life Science, Ben Gurion University, Israel) for providing the recombinant clone, Anabaena PCC 7120\#11. This project was partially funded by a National Research Foundation grant awarded to GB. We thank anonymous reviewers for comments that improved this manuscript

Received: 8 July 2012 Accepted: 27 September 2012

Published: 4 October 2012

\section{References}

1. Coetzee M, Craig M, le Sueur D: Distribution of African malaria mosquitoes belonging to the Anopheles gambiae complex. Parasitol Today 2000, 16:74-77.

2. Gillies MT, De Meillon B: The Anophelinae of Africa South of the Sahara. Publication no. 54. Johannesburg: South African Institute for Medical Research; 1968.

3. Walker K, Lynch M: Contributions of Anopheles larval control to malaria suppression in tropical Africa: review of achievements and potential. Med Vet Entomol 2007, 21:2-21

4. Awolola TS, Oduola OA, Strode C, Koekemoer LL, Brooke B, Ranson H: Evidence of multiple pyrethroid resistance mechanisms in the malaria vector Anopheles gambiae sensu stricto from Nigeria. Trans $R$ Soc Trop Med Hyg 2009, 103:1139-1145.

5. Hargreaves K, Hunt RH, Brooke BD, Mthembu J, Weeto MM, Awolola TS, Coetzee M: Anopheles arabiensis and An. quadriannulatus resistance to DDT in South Africa. Med Vet Entomol 2003, 17:417-422.

6. Okoye PN, Brooke BD, Koekemoer LL, Hunt RH, Coetzee M: Characterization of DDT, pyrethroid, and carbamate resistance in Anopheles funestus from Obuasi, Ghana. Trans R Soc Trop Med Hyg 2008, 102:591-598.

7. Federici BA, Park HW, Bideshi DK, Wirth MC, Johnson JJ: Recombinant bacteria for mosquito control. J Exp Biol 2003, 206:3877-3885.

8. Goldberg $\sqcup$, Margalit J: A bacterial spore demonstrating rapid larvicidal activity against Anopheles serengetii, Uranotaenia unguiculata, Culex univittatus, Aedes aegypti and Culex pipiens. Mosq News 1977, 37:355-358.

9. Schnepf E, Crickmore N, Van Rie J, Lereclus D, Baum J, Feitelson J, Zeigler $\mathrm{DR}$, Dean DH: Bacillus thuringiensis and its pesticidal crystal proteins. Microbiol Mol Biol Rev 1998, 62:775-806.

10. Takken W, Knols B: Malaria vector control: current and future strategies. Trends Parasitol 2008, 25:101-104.

11. Becker N, Zgomba M, Ludwig M, Petric D, Rettich F: Factors influencing the activity of Bacillus thuringiensis var. israelensis treatments. J Am Mosa Control Assoc 1992, 8:285-289.

12. Ohana B, Margalit J, Barak Z: Fate of Bacillus thuringiensis subsp. israelensis under stimulated field conditions. Appl Environ Microbio/ 1987 53:828-831.

13. Manasherob R, Otieno-Ayayo ZN, Ben-Dov E, Miaskovsky R, Boussiba S, Zaritsky A: Enduring toxicity of transgenic Anabaena PCC 7120 expressing mosquito larvicidal genes from Bacillus thuringiensis subsp. israelensis. Environ Microbiol 2003, 5:997-100.

14. Armengol G, Guevara OE, Orduz S, Crickmore N: Expression of Bacillus thuringiensis mosquitocidal toxin Cry11Aa in the aquatic bacterium Asticcacaulis excentricus. Current Microbiol 2005, 51:430-433.

15. Xiaoqiang W, Vennison SJ, Huirong L, Ben-Dov E, Zaritsky A, Boussiba S: Mosquito larvicidal activity of transgenic Anabaena strain PCC 7120 expressing combinations of genes from Bacillus thuringiensis subsp. israelensis. Appl Environ Microbiol 1997, 63:4971-4974.

16. Lluisma AO, Karmacharya N, Zarka A, Ben-Dov E, Zaritsky A, Boussiba S: Suitability of Anabaena PCC 7120 expressing mosquitocidal toxin genes from Bacillus thuringiensis subsp. israelensis for biotechnological application. Appl Microbiol Biotechnol 2001, 57:161-166.

17. Finney DJ: Probit analysis. 3rd edition. London: Cambridge University Press; 1971.

18. Champ BR, Campbell-Brown MJ: Insecticide resistance in Australian Tribolium castaneum (Herbst) - A test method for detecting insecticide resistance. J Stored Prod Res 1970, 6:53-70.

19. Jyoti $J$, Brewer $G$ J: Median lethal concentration and efficacy of Bacillus thuringiensis against banded sunflower moth (Lepidoptera: Tortricidae). J Econ Entomol 1999, 92:1289-1291.
20. Otieno-Ayaya ZN, Zaritsky A, Wirth MC, Manasherob R, Khasdan V, Cahan R, Ben-Dov E: Variations in the mosquito larvicidal activities of toxins from Bacillus thuringiensis ssp. israelensis. Environ Microbiol 2008, 10:2191-2199.

21. Merritt RW, Dadd RH, Walker ED: Feeding behavior, natural food, and nutritional relationships of larval mosquitoes. Annu Rev Entomol 1992, 37:349-376.

22. Ben-Dov E, Nissan G, Pelleg N, Manasherob R, Boussiba S, Zaritsky A: Refined, circular restriction map of the Bacillus thuringiensis subsp. israelensis plasmid carrying the mosquito larvicidal genes. Plasmid 1999 42:186-191.

23. Delécluse A, Poncet S, Klier A, Rapoport G: Expression of cryIVA and cryIVB genes, independently or in combination, in a crystal-negative strain of Bacillus thuringiensis subsp. israelensis. App/ Environ Microbio/ 1993, 59:3922-3927

24. Poncet S, Delécluse A, Klier A, Rapoport G: Evaluation of synergistic interactions among the CryIVA, Cry IVB, and CryIVD toxic components of Bacillus thuringiensis subsp. israelensis crystals. J Inverterbr Pathol 1995, 66:131-135.

25. Ketseoglou I, Koekemoer $L L$, Coetzee M, Bouwer G: The larvicidal efficacy of Bacillus thuringiensis subsp. israelensis against five African Anopheles (Diptera: Culicidae) species. Afr Entomol 2011, 19:146-150.

26. Hofmann C, Vanderbruggen $H$, Hófte $H$, Van Rie J, Jansens S, Van Mellaert $H$ : Specificity of Bacillus thuringiensis $\delta$-endotoxins is correlated with the presence of high-affinity binding sites in the brush border membrane of target insect midguts. Proc Natl Acad Sci USA 1988, 85:7844-7848.

27. Van Rie J, Jansens S, Hófte H, Degheele D, Van Mellaert H: Receptors on the brush border membrane of the insect midgut as determinants of the specificity of Bacillus thuringiensis delta-endotoxins. Appl Environ Microbiol 1990, 56:1378-1385.

28. Perez C, Fernandez LE, Sun JG, Folch JL, Gill SS, Soberon M, Bravo A: Bacillus thuringiensis subsp. israelensis Cyt1Aa synergizes Cry11Aa toxin by functioning as a membrane-bound receptor. Proc Natl Acad Sci USA 2005, 102:18303-18308.

doi:10.1186/1756-3305-5-220

Cite this article as: Ketseoglou and Bouwer: The susceptibility of five African Anopheles species to Anabaena PCC 7120 expressing Bacillus thuringiensis subsp. israelensis mosquitocidal cry genes. Parasites \& Vectors 2012 5:220

\section{Submit your next manuscript to BioMed Central and take full advantage of:}

- Convenient online submission

- Thorough peer review

- No space constraints or color figure charges

- Immediate publication on acceptance

- Inclusion in PubMed, CAS, Scopus and Google Scholar

- Research which is freely available for redistribution 